\title{
ANALYSIS OF CROSS-BORDER COOPERATION IN THE CONTEXT OF SUSTAINABLE REGIONAL DEVELOPMENT
}

\author{
Oleksandr Diakoniuk \\ 1 Stefan cel Mare University, Faculty of Economic Sciences and Public Administration, \\ Doctoral school of socio-human sciences, Suceava, Romania \\ alex.dyakonyuk@gmail.com
}

\begin{abstract}
The purpose of the article is to study the aspects of cross-border cooperation, analyzing the existing situation, barriers and difficulties in cross-border cooperation in the context of sustainable development. To carry out the research, the following methods were used: general scientific methods, in particular: generalization methods - for researching the essence and features of cross-border cooperation; systematization method - to determine the types of formation and implementation of interregional cooperation; Today, despite the development priorities and the main measures highlighted, there are a number of discouraging elements in practice. These are hidden in cross-border imbalances (social, technological and economic potential; information resources; human and social capital; institutional rules, laws and procedures), which do not allow for a long time further socioeconomic development problems. The study of the development of European programs for regional development and cross-border economic cooperation allows to determine the important role of the institutional component of sustainable development, which has an effective impact on the environment of cross-border imbalances. The results of the study aim to develop the practice of cross-border cooperation in the context of cross-border imbalances in the context of sustainable development.
\end{abstract}

Keywords: Cross - border cooperation, cooperation programs, cross - border region, sustainable development.

JEL Classification: F2, F3, F5, O18

\section{Introduction}

The need to address common problems in the cross-border region - adjacent border areas of neighboring states, such as: improvement and development of cross-border infrastructure, environmental protection, shared use of water resources, spatial planning, requires mutual and beneficial action in same time for both parties. At the same time, improving and deepening cross-border cooperation opens up new opportunities and reserves for intensifying economic activity in the peripheral territories of the regions, mobilizing the potential of natural resources and increasing competitiveness. These factors also guide the need to coordinate the development of cross-border regions.

One of the ways to achieve the objectives of local and regional development in the conditions of the new territorial organization of power is to intensify cross-border cooperation. In this context, we are talking about strengthening economic and humanitarian ties between the EU border and adjacent countries, inter-territorial cooperation in solving common problems, implementing joint cross-border projects and initiatives to realize the development potential of adjacent territories.

However, in order for border areas to use their geographical location and cross-border links as a competitive advantage, urgent issues need to be addressed in cross-border cooperation. This involves a series of steps to ensure cross-border cooperation on an inclusive transparent basis, the implementation of effective state support and the assistance 
of territorial communities to achieve a sufficient level of competitiveness in the "fight for European funds".

\section{Current state of cross-border cooperation}

Cross-border cooperation generates a high level of interaction between neighboring countries, which leads to the creation of a safer and more predictable regional space (Rădoi, 2020).

Cross-border cooperation can be defined as "any type of concerted action between public and / or private institutions of border regions in two (or more) states" (Sousa, 2012).

At the heart of cross-border cooperation is the process of establishing links and contractual relations in border areas to find solutions to common and identical problems, and the "philosophy of cross-border cooperation" is that two adjacent border regions cooperate in developing plans and priorities, expand together, rather than working separately and then reaching an agreement on economic development plans. Cross-border cooperation consists in involving all social groups and administrative bodies for economic growth (Cross-border Collaboration and Portfolio Management of Research Infrastructures, 2017).

The Madrid Convention defines cross-border cooperation as "any joint action aim to strengthen and deepen good neighborly relations between territorial communities or authorities under the jurisdiction of two or more Contracting Parties and concluding any agreements necessary for this purpose" (Official Journal of the European Union, 2012).

There are four levels of implementation of cross-border cooperation:

- at international level: the policy of common European interests is implemented, the coordination of national regional policies for a balanced development of the European space is achieved;

- at state level: a national policy is designet to develop the cross-border cooperation and national interests are harmonized with the European ones, as well as the harmonization of national and regional objectives;

- at regional level: the regional policy of cross-border cooperation is implemented taking into account the interests of the state and local authorities, the coordination of actions between the regions of neighboring countries is achieved;

- at local level: the coordination of local government development plans is done with significant attention to regional and national interests, there is a concrete cooperation between the subjects of border areas.

Cross-border cooperation has become a factor that promotes social equality and is a tool for the development of all activities of local and regional border authorities in and today is introduced in various aspects of daily life in Europe (Medeiros, 2019).

- Cross-border cooperation is a specific field of international economic, political, environmental, cultural, educational and other international activities carried out at regional level, which, covering all general forms, have the following characteristics: presence of the border and the need for its arrangement, shared use of natural resources and finding a common solution to eliminate environmental security problems, wider mutual communication of neighboring populations and personal connections, and last but not least a much greater emphasis on infrastructure (roads, services sector, road infrastructure) (Nienaber \& Wille, 2019).

\section{Cross-border cooperation in the form of Euroregions}

The most widespread form of cross-border cooperation in Europe is considered to be crossborder cooperation in the form of Euroregions. Euroregions are characterized as a form of cross-border cooperation between local or regional authorities in two or more states with a common border, which aims to coordinate mutual efforts and implement measures agreed in different spheres of life in accordance with national laws and international law to address 
common issues and in the interests of people living in its territory in different ways. sides of the state border.

Cooperation within the Euroregions promotes the development of integration processes in the cultural, educational, economic, communication and other spheres, creates opportunities to accelerate the adaptation of European legislation, determines an increase in the living standard of the population located on the border territories.

Due to the functioning of the Euroregions, a mechanism for the formation and development of international economic relations in cross-border regions can be created, this being presented in figure no. 1

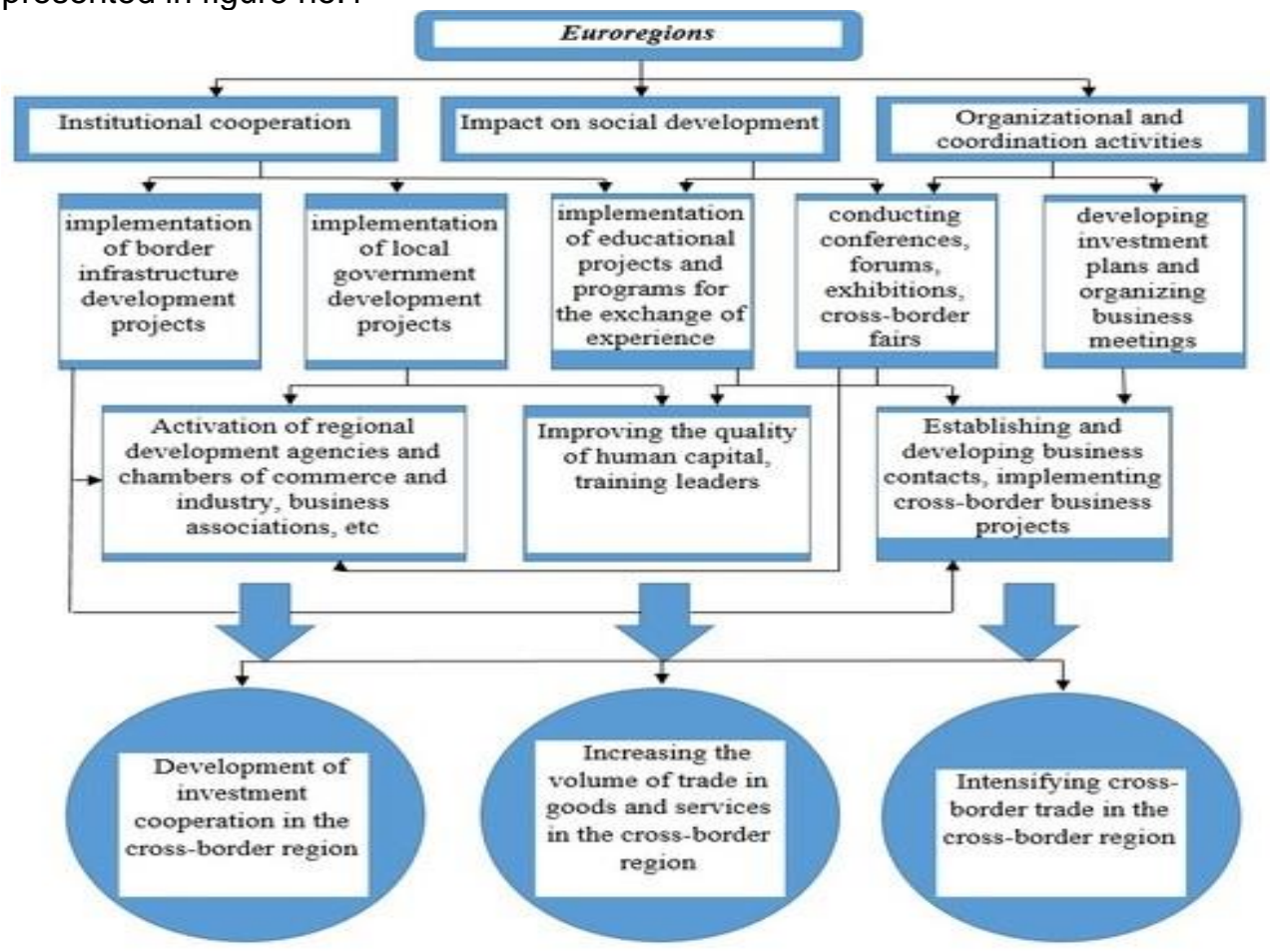

Figure no. 1 The mechanism of formation and development of international economic relations in cross-border regions

Source: own processing according to Practical guide of cross-border cooperation

The characteristics of the functioning of Euroregions as a form of cross-border cooperation are:

- Legal aspects of the functioning of Euroregions - the creation of a Euroregion does not lead to a new administrative-territorial entity with the status of legal person, the legal regulation of each member of the Euroregion is carried out in accordance with the current legislation of the state to which it belongs. they have no power to replace the authorities operating in the territory of other Member States.

- Euroregions do not act against the interests of the national state, they are not supranational entities, in their activities they do not replace the foreign policy functions of the states (political features).

- In the vast majority of cases, Euroregions cover territories that have a common historical past and have even been part of a state; Euroregions sometimes include territories that in the past belonged to a state, was contested by a neighboring one, which has a common border with it (historical features). 
- The Euroregion usually contains multinational territories or regions inhabited by members of several ethnic groups. In many cases, adjacent border regions host a national minority, which represents the national majority of the country on the other side of the border (characteristics related to the ethnic composition of border areas).

- The territories or regions that make up the Euroregions are peripheral to the administrative centers in their countries.

- All territories or regions that are part of the Euroregions have common cross-border issues that require a concerted effort by the territorial communities or the authorities of the neighboring countries. Usually, such issues include environmental protection, development of border infrastructure, transport and communications, rational use of labor resources, ensuring the conditions for the development of ethnic minorities.

- Existence of clearly defined common interests of Euroregion members. Typical for this group are the commercial and economic interests, taking into account the place of the member regions in the interterritorial division of labor, in the field of common development of tourism, mutual services across the state border, creation of a network of cooperation in science, education and culture. The definition of a common space development strategy is a universal area of common interest for the members of any Euroregion.

\section{Barriers and difficulties in cross-border cooperation}

Despite the high importance of cross-border cooperation in regional development, it is important to note the existence of systemic shortcomings of state policy in this area, which make it impossible to use it effectively in regional development.

The main barriers and problems in cross-border cooperation can be: legal and administrative barriers; language barriers; difficulties crossing the border; economic inequalities; lack of interest in cooperation of the authorities; socio-cultural differences; lack of trust; other barriers. Therefore, I will present in more detail some issues in cross-border cooperation.

Problems of creation and development of European territorial cooperation associations in different non-EU countries.

Here we note the lack of awareness of communities about the essence of these cross-border cooperation, the legal algorithm for their creation and the opportunities they offer.

There is no methodological support for communities (no methodological recommendations developed for the formation of cross-border cooperation between EU and partner countries) and information among communities with the involvement of specialists and experts to inform representatives of cities, villages and territorial communities. In addition, a significant shortcoming is the non-use at local level of the practice of organizing business meetings of representatives of local communities abroad (in regions with experience in establishing cross-border cooperation), to learn experience and study this organizational form of crossborder cooperation. "inside" border.

Information support.

A separate issue in the development of organizational forms of cross-border cooperation (typical of both Euroregions and other types of cooperation) is, in general, the insufficient level of interactive information assistance and support of cross-border associations, which is characterized by:

- the low frequency of updating of websites specific to cross-border cooperation or their absence;

- the insufficient presence of the information base on cross-border cooperation on social networks and the lack of opportunities to distribute audiovisual material on popular video services (eg YouTube); 
- low level of reflection in the information space of successful cases and projects implemented in cross-border cooperation, which could help to promote its positive image and, in general, to promote different forms of cross-border cooperation.

Issues related to the non-use of the potential of cross-border and territorial cooperation programs within the implementation of regional / local development strategies. The use of cross-border cooperation as an effective tool for regional development is hampered by the lack of a unified approach to cross-border component reflection in regional and local development programs and strategies, which restricts both the possibilities of coordinating them with cross-border cooperation programs for 2021-2027. and the opportunity to realize the competitive advantages associated with their position at the border.

\section{Factors underlying the creation of the cross-border cooperation strategy}

Analyzing the European Union's regional development policy, one can identify a set of important factors that emphasize the creation of a development strategy.

- The existing economic conditions are taken into account.

European experience clearly shows that a level playing field for business and other economic activities, offered at European level and in the common market, is fundamental to the development of the EU economy. At the same time, the success of growth strategies depends to a large extent on their interaction with individual national strategies related to specific sectors: taxes, the labor market and so on. Favorable macroeconomic conditions and an appropriate microeconomic environment (regulatory policy, business climate) are preconditions for the implementation of effective strategies to help lagging regions. If the strategies of national governments aim to limitin the independence of the regions, then the resources that could be directed towards their economic development are spent on combating the higher authorities.

- Development of individual strategies with a set of appropriate measures.

The accumulation and development of knowledge and skills in the region is a decisive factor that can ensure the long-term development of the region. Therefore, economic development strategies must be developed taking into account the specifics of the region, adapting them to the needs and aspirations of its inhabitants. From the wide variety of means to achieve the goal, it is necessary from the outset to form an appropriate set of measures aimed at implementing such an individual strategy. Although prestigious investment projects play an important role and can be a starting point or a catalyst for future benefits.

- Stability of funding and coordination of programs.

The key to the successful implementation of regional programs in the EU is the planning period, which is set by adopting an appropriate budget to fund them. This ensures the longterm stability of investment in projects, thanks to the strategic vision and protection against political changes.

- The need for international cooperation.

Stimulating cross-border and interregional cooperation is an element of the EU's regional policy since its establishment, it contributes significantly to the regional development of the constituent parts of the Union. On one hand, the opportunity to encourage constructive contacts between regions beyond the EU's external borders has helped many countries to properly prepare for EU accession responsibilities and has shaped the positive attitudes of their citizens towards future accession. On the other hand, cooperation between regions within EU borders has strengthened relations between territorial communities, sometimes relatively divided or isolated. The ability to bring together the regions of several countries with common problems contributes to a practical and constructive approach to common development.

- Recognition of the positive and negative consequences of urbanization. 
In Europe, as in other parts of the world, urban agglomerations (or areas of large cities) are seen as key factors in economic growth. The European experience demonstrates the ambiguous effects of economic concentration on the spatial development of countries. Europe, with its relatively high population density and high land prices, faces challenges from large cities, such as overcrowding, pollution and crime. Therefore, the economic benefits of urbanization must be weighed against the costs associated with solving these problems.

- The importance of small and medium-sized cities.

Europe is convinced that economic growth is not just about big cities. The role of mediumsized cities is to combine large and small cities and remote rural areas into a single entity. Medium-sized cities also play an important role in promoting integration, developing connections and strengthening economies of scale. Their equally important function is to reduce the depopulation of rural areas.

- Emphasis on job creation and capital formation.

Local development plays an important role in stimulating economic growth in underdeveloped regions. Significant poverty reduction in these areas can be achieved by developing programs that involve the creation of new jobs. In addition, Europe is characterized by relatively low geographical mobility of workers. As a result, strategies to promote local employment and capacity-building initiatives so that underdeveloped regions can reap the benefits of direct links with the general economy.

\section{Conclusions}

In general, cross-border cooperation between the European Union and third countries is achieved through certain cooperation programs. These programs largely enable the sustainable economic growth of the participating countries.

For the successful implementation of cross-border cooperation programs, it is necessary to create a favorable environment that involves:

- the existence of a high-speed communication infrastructure, such as airports, motorway networks, high-speed internet access, etc., which will facilitate the mobility of people and goods;

- the availability of specific resources that distinguish these regions and constitute their difference; such factors may be the emergence of transnational companies that have a prestigious brand, whose location attracts other companies and causes a cumulative effect; the concentration of such enterprises develops a certain industrial culture, increases the qualification of employees, product quality, promotes cooperation, activates training mechanisms. A significant element here is the position of transnational firms and the degree of their territorialization, as these firms can greatly facilitate the entry of local enterprises into global networks;

- the presence of a number of institutions and organizations engaged in the provision of services in the international sphere, this refers to the activities of export-import enterprises, the activities of various training centers in the field of international development and management;

- the existence of public and private organizations that facilitate international trade, such as exporters' clubs, international services of chambers of commerce and industry, etc.

In the context of regional development, the important directions for deepening cross-border cooperation must be to stimulate new forms of business, activate investment potential, create new jobs, build high-quality infrastructure and improve the quality of life. Considerable attention must be paid to the formation of technology parks, the introduction of new technologies, etc. 


\section{Bibliography}

1. Birte Nienaber \& Christian Wille (2019): Cross-border cooperation in Europe: a relational perspective, European Planning Studies, DOI: 10.1080/09654313.2019.1623971

2. Cross-border Collaboration and Portfolio Management of Research Infrastructures, 2017, available online

https://www.scienceeurope.org/media/ptllv4b/se ws report research infrastructures cbc.pdf

3. Cross-border economic developement, Practical guide, 2015, available online at http://www.espacestransfrontaliers.org/fileadmin/user upload/documents/Documents MOT/Etudes Publications MOT/GUIDE PRATIQUE DEV ECO EN.pdf

4. Eduardo Medeiros (2020) Delimiting cross-border areas for policy implementation: a multifactor proposal, European Planning Studies, 28:1, 125-145, DOI: 10.1080/09654313.2019.1687654

5. Ilie Rădoi (2020): European Capital of Culture, Urban Tourism and CrossBorder Cooperation Between Romania and Serbia, DOI: 10.1080/19448953.2020.1778881

6. Luis de Sousa (2012), Understanding European Cross-border Cooperation: A Framework for Analysis, DOI:10.1080/07036337.2012.711827

7. Official Journal of the European Union, 2012, available online at https://eur-lex.europa.eu/ 